\title{
Política social e emancipação humana no capitalismo contemporâneo: reflexões marxistas
}

\author{
Social policy and human emancipation in contemporary capitalism: \\ Marxist reflections
}

\section{Thais Soares CARAMURU*}

Resumo: À luz do debate que atualmente inquieta estudiosos/as da política social, especialmente no âmbito do Serviço Social brasileiro, este artigo teve o objetivo geral de traçar algumas diretrizes do debate marxista sobre emancipação política e emancipação humana e, como objetivo específico, pretendeu sinalizar algumas proposições relacionadas a como a política social pode se constituir em mediação para a emancipação humana. Com base em pesquisa de tipo bibliográfica, em que se abordaram diferentes concepções de autores marxistas sobre o tema, apresentaram-se três sugestões a respeito da funcionalidade da política social nas lutas revolucionárias. Para além do juízo de valor a ser feito acerca do que foi proposto, argumenta-se que a política social faz parte do cotidiano da classe trabalhadora e, por isso, deve ser concebida como mediação para a busca pela emancipação humana.

Palavras-chave: Política social. Emancipação humana. Emancipação política. Marxismo.

Abstract: In the light of the debate that currently preoccupies social policy scholars, especially in the scope of Brazilian Social Work, this article had the general objective of outlining some guidelines to the Marxist debate on political and human emancipation and, as a specific purpose, it intends to signal some propositions concerning how social policy can become an instrument to attain human emancipation. After bibliographical research, in which different interpretations of Marxist authors on the subject were approached, three suggestions are presented regarding the functionality of social policy in revolutionary struggle. Beyond the value judgement of these suggestions, the article argues that social policy is part of the reality of the working class and, because of that, it should be perceived as an instrument of mediation in the search for human emancipation.

Key words: Social policy. Human emancipation. Political emancipation. Marxism.

Submetido em: 30/4/2018. Aceito em: 8/8/2018.

\section{INTRODUÇÃO}

$\mathrm{D}$ entre as diversas conquistas teóricas e políticas da magistral obra de Karl Marx, uma das mais instigantes consiste na concepção, exposta no Manifesto Comunista ${ }^{1}$, de que "[...] a história de todas as sociedades até hoje existentes é a história das lutas de classes" (MARX; ENGELS, 2010, p. 40). Na sociedade burguesa, que se estrutura sob a exploração da classe trabalhadora pela classe detentora dos meios de produção, o prol etariado tem um papel especificamente revolucionário, direcionado à abolição da ordem social e à conquista de sua emancipação em relação à opressão capitalista.

\footnotetext{
* Economista. Doutoranda em Política Social no Programa de Pós-Graduação em Política Social da Univ ersidade de Brasília (UnB, Brasília (DF) Brasil). UnB. Campus Universitário Darcy Ribeiro, Departamento de Serviço Social (SER). ICC Norte, Brasília (DF), CEP.: 7 0910.900. E-mail: <tcaramuru@gmail.com>. ORC ID: <http://orcid.org/oooo-0002-6828-1377>.

${ }^{1}$ Recorde-se que, em 2018, celebram-se 200 anos do nascimento de Marx e, também, 170 anos da publicação do Manifesto Comunista.
} 
Com base no contexto da complexa realidade social engendrada pelas configurações contemporâneas do capitalismo, o debate marxiano sobre emancipação política e emancipação humana - colocado no artigo intitulado Sobre a questão judaica, constante em Marx (2010) - tem sido retomado por intelectuais que, desde o campo marxista, refletem acerca do caráter da luta de classes na presente quadra histórica.

Particularmente, no âmbito do Serviço Social brasileiro, tal debate tem sido recuperado para refletir acerca do sentido das políticas sociais no capitalismo, fundamentalmente a partir de dois eixos argumentativos. Por um lado, há pesquisadores que interpretam que as políticas sociais podem se constituir em instrumentos para a conquista da emancipação humana, que seria a plena emancipação da classe trabalhadora em relação ao capital. Por outro lado, há setores que defendem que as políticas sociais possuem um papel demasiadamente limitado, na medida em que garantem uma emancipação apenas compatível com a manutenção das relações de produção burguesas, ou seja, a emancipação política.

À luz de tal problemática, este artigo tem como objetivo geral traçar algumas diretrizes do debate marxista sobre emancipação política e emancipação humana no capitalismo e, como objetivo específico, pretende sinalizar proposições acerca de como a política social pode se constituir em mediação para a emancipação humana. A hipótese de trabalho adotada é a de que a política social pode ser um dos múltiplos mecanismos que devem compor o amplo, complexo e imprescindível projeto revolucionário da classe oprimida pelo capital. O tipo de pesquisa realizado para elaboração do texto será de caráter bibliográfico.

O tema mostra-se relevante para reflexão teórica e política nesse contexto histórico de agudização da crise capitalista, especialmente em relação à conjuntura brasileira de avanço do conservadorismo e de potencialização da ofensiva capitalista contra a classe trabalhadora, cujo ataque aos benefícios e serviços sociais é, apenas, uma das múltiplas dimensões.

Em consonância com a natureza do objeto aqui problematizado, a perspectiva teóricometodológica a ser adotada corresponde à visão de mundo marxista, fundada na dialética materialista, a qual concebe o movimento da sociedade burguesa como constante, permanente e contraditório e, justamente por isso, sustenta a possibilidade de transformar a ordem estabelecida, "[...] porque apreende cada forma existente no fluxo do movimento, portanto também com seu lado transitório; porque não se deixa impressionar por nada e é, em sua essência, crítica e revolucionária” (MARX, 1983, p. 21).

Além dessa introdução e das considerações finais, os elementos textuais do artigo estão segregados em duas seções: a primeira está destinada à colocação do debate marxista sobre a temática; a segunda apresenta algumas proposições sobre como as políticas sociais podem mediar as lutas revolucionárias pela emancipação humana.

\section{Colocação do debate marxista}

Como primeiro passo para abordagem do objeto estabelecido, é primordial que se faça um brevíssimo resgate sobre emancipação política e emancipação humana, a partir do texto de Marx (2010). Em sequência, serão apresentadas as concepções de autores marxistas acerca do debate quanto à funcionalidade ou não da política social como mediação para alcance da

Argum., Vitória, v. 10, n. 2, p. 148-160, maio/ago. 2018. 
emancipação humana, com enfoque nas análises de Lessa (2007), Tonet (2015) e Boschetti (2016).

O artigo intitulado Sobre a questão judaica ${ }^{2}$ foi originalmente publicado por Marx (2010) em 1844 nos Anais Franco-Alemães, com o objetivo de apresentar uma crítica ao texto A questão judaica, publicado em 1842 por Bruno Bauer ${ }^{3}$. Trata-se de um contexto histórico de decomposição do Estado Absolutista e de reivindicação de direitos civis e políticos no espaço geográfico em que hoje se encontra a Alemanha ${ }^{4}$, onde estava ocorrendo um amplo debate social e intelectual acerca do tema, especialmente em relação ao acesso dos judeus aos direitos de cidadania que conformavam a base do Estado político burguês (BENSAÏD, 2010).

Em linhas gerais, o epicentro da crítica de Marx (2010) a Bruno Bauer se constitui no fato de que esse último aborda a questão da emancipação política do judeu de uma forma fundamentalmente teológica, pressupondo que há uma incompatibilidade entre a religião e os direitos humanos estabelecidos pelo Estado político burguês e que, portanto, o acesso à cidadania pelos judeus dependeria da conversão destes em ateus. Na concepção de Marx (2010), tal abordagem de Bauer sobre a temática era profundamente restritiva e unilateral, pois a questão central não diz respeito a quem deva ser emancipado ou quem promove a emancipação, mas se relaciona com a espécie de emancipação exigida e, nesse âmbito, o problema da questão judaica deve levar em consideração a relação entre emancipação política e emancipação humana e os elementos que compõem a essência de cada tipo de emancipação.

Marx (2010) demonstra que a emancipação política é revestida por limitações e contradições estruturais, pois, em sua essência, existem as condições materiais que regem a sociedade burguesa. Essa questão é problematizada pelo autor de duas formas. Primeiro, apontando que o Estado político burguês se torna laico sem que o homem membro da sociedade burguesa se liberte das condições materiais que o fazem buscar a religião, de modo que, nos marcos da sociedade burguesa, a limitação da emancipação política "[...] fica evidente de imediato no fato de o Estado ser capaz de se libertar de uma limitação sem que o homem realmente fique livre dela" (MARX, 2010, p. 38-39).

Ademais, a análise marxiana descortina a limitação da emancipação política com base na análise dos direitos políticos e civis que compunham as Declarações dos Direitos do Homem e do Cidadão de 1791 e de 1793. À luz de tais documentos, Marx (2010) aponta que os assim chamados direitos humanos, como o direito à igualdade, à segurança e à liberdade de prática religiosa, se constituem em direitos do membro da sociedade burguesa, os quais não superam o homem egoísta, regido pelo interesse privado e pela necessidade de manutenção da propriedade privada. Nos marcos de tais limitações, o autor reconhece que a emancipação política representa um grande progresso: “[...] não chega a ser a forma definitiva da emancipação humana em geral, mas constitui a forma definitiva da emancipação humana dentro da ordem mundial vigente até aqui”. (MARX, 2010, p. 41).

\footnotetext{
2 Alerta-se que a síntese aqui exarada é extremamente limitada, haja vista que as restrições do objeto e da extensão deste artigo não permitem uma abordagem abrangente acerca desta extraordinária obra marxiana. 3 Tex to disponível no seguinte sítio eletrônico:<www.blogdaboitempo.com.br >. Acesso em: 30 abr. 2018. 4 Recorde-se que a Alemanha apenas se tornou um Estado unificado em 1871.
}

Argum., Vitória, v. 10, n. 2, p. 148-160, maio/ago. 2018. 
Dessas questões é possível depreender que a essência da emancipação política se encontra nos marcos da sociedade burguesa e na manutenção dos elementos materiais sob os quais tal ordem social está estruturada, como a propriedade privada e a separação de seus membros entre detentores dos meios de produção, que compram e exploram força de trabalho e aqueles que vivem, apenas, da venda da própria força de trabalho.

No que tange à essência da emancipação humana, Marx (2010) aponta que tal modo de emancipação é isento de contradições e, nesse âmbito, rompe com a formulação teológica feita por Bruno Bauer acerca da questão judaica, pois aponta que a abolição do judaísmo e da religião em geral é equivalente à relação do judaísmo com a emancipação da ordem social moderna. Tendo em vista que o judaísmo está fundamentado na necessidade prática e no interesse próprio, em um contexto no qual seu culto secular é o negócio e o seu Deus secular é o dinheiro, a emancipação humana do judeu não ocorrerá, simplesmente, quando este abrir mão da religião, mas, somente, quando a organização da sociedade superar os pressupostos do negócio e do dinheiro: "[...] agora sim! A emancipação em relação ao negócio e ao dinheiro, portanto, em relação ao judaísmo prático, real, seria a autoemancipação da nossa época" (MARX, 2010, p. 56, grifos do autor).

Em última instância, na concepção marxiana, a essência da emancipação humana representa a superação das leis que regem a sociedade burguesa, ou seja, somente será alcançada quando o homem superar a necessidade prática de manter a ordem social fundada na propriedade privada e converter-se em ente genérico na sua vida empírica, no seu trabalho individual e nas suas relações individuais (MARX, 2010).

Feito esse breve resgate acerca da diferença fundamental entre a essência da emancipação política e da emancipação humana, cumpre abordar as divergências entre autores marxistas acerca do papel que a política social pode exercer - ou não - no caminho para a emancipação humana.

Lessa $(2007)^{5}$ se propõe a fazer uma análise das relações entre emancipação política e emancipação humana no contexto do aprofundamento da crise contemporânea do capital, que se alastra por todas as esferas da vida social. O autor inicia sua incursão no tema fazendo uma abordagem teórica a respeito das diferenças entre emancipação política e emancipação humana, e do papel do Estado político em garantir a manutenção da propriedade privada, nos termos de Marx (2010).

Em sua interpretação, a emancipação política está intrinsecamente relacionada à manutenção da propriedade privada burguesa e, nesse passo, o autor concebe que todas as conquistas alcançadas nesse âmbito representam a cooptação dos trabalhadores: “[...] a emancipação política, portanto, é a realização histórica da sociabilidade regida pela propriedade privada burguesa na qual os homens não passam de 'joguetes' de seus 'poderes alienados"' (LESSA, 2007, p. 4). Circunstanciado nessa assertiva, o autor afirma que, na presente quadra histórica, a redução de direitos ocorrida sob a égide da ofensiva neoliberal não representa a revoga-

\footnotetext{
5 Artigo proveniente de notas redigidas antes e sistematizadas após o XEncontro Nacional de Pesquisadores em Serviço Social (ENPESS) e, posteriormente, publicado pelo autor na Revista Serviço Social e Sociedade, de junho de 2007.
}

Argum., Vitória, v. 10, n. 2, p. 148-160, maio/ago. 2018. 
ção ou redução da emancipação política, mas é plenamente compatível com o que a cidadania, o Estado político e a emancipação política representam como pressupostos da garantia da propriedade privada, nos marcos da crise estrutural do capital.

O argumento central de Lessa (2007) gira em torno da negação histórica entre emancipação política e emancipação humana, de modo que as lutas dos trabalhadores devem direcionarse à superação da ordem burguesa, sem que haja nenhum tipo de articulação entre ambas as espécies de emancipação. Assim, o autor defende que toda e qualquer proposta de "[...] radicalização da 'cidadania' somente conduzirá a uma cidadania mais radical, mas jamais à superação do Estado, da propriedade privada e do casamento monogâmico - que é a plataforma histórica da emancipação humana" (LESSA, 2007, p. 9). Em última instância, para Lessa (2007), as lutas pela emancipação humana devem deslocar-se de todo o aparato estatal em direção ao terreno extraparlamentar, de modo que toda e qualquer luta que implique o caminho por dentro do Estado constitui-se em equívoco politicista e idealismo de Estado.

Tonet (2015) reconhece o caráter contraditório das políticas e dos direitos sociais, na medida em que estes não são meras concessões do Estado burguês e constituem-se em resultado direto das lutas entre capital e trabalho e, ao mesmo tempo, não superam os limites impo stos pela reprodução capitalista, pois seu fundamento ontológico é o ato de compra e venda da força de trabalho. Reconhecendo os limites da política social como mecanismo inserido na emancipação política, o autor problematiza a questão relacionada às possibilidades e limites da política social como caminho para a emancipação humana.

Nesse sentido, Tonet (2015) aponta que a questão não pode ser abordada de modo abstrato, mas deve levar em consideração o caráter contemporâneo das lutas de classes. Sob tal contexto, o autor argumenta que a adoção da via reformista - isto é, da coexistência pacífica com o capitalismo - pelos movimentos dos trabalhadores culminou em prejuízo teórico e prático da perspectiva revolucionária impulsionada pelo marxismo e isto, por sua vez, culminou na ausência da classe operária como classe dirigente da revolução. Na concepção do autor, a única forma de a política social adquirir alguma conexão com as lutas pela emancipação humana é em uma conjuntura na qual a classe operária recupere o seu papel como classe dirigente da luta social. "Enquanto isso não ocorrer, as lutas dos trabalhadores tenderão, como já afirmamos, a assumir um caráter de resistência e, infelizmente, de recuo frente às investidas do capital" (TONET, 2015, p. 292).

Reconhecendo as radicais diferenças entre emancipação política e emancipação humana, Tonet (2015) aponta duas tarefas fundamentais às lutas pela superação do capitalismo na complexa realidade social contemporânea: uma teórica e outra prática. O desafio teórico, segundo o autor, consiste em retomar a perspectiva revolucionária e da classe operária como seu sujeito fundamental, especialmente por meio da retomada da centralidade ontológica do trabalho e da recuperação da visão de mundo marxiana. Como tarefa prática, o autor destaca que o epicentro das lutas revolucionárias deve ser a esfera extraparlamentar, não no sentido de rejeitar os caminhos por dentro do Estado capitalista, mas de subordinar estes às disputas extraparlamentares.

Argum., Vitória, v. 10, n. 2, p. 148-160, maio/ago. 2018. 
No âmbito de sua análise acerca da natureza do Estado social capitalista ${ }^{6}$, Boschetti (2016) aponta alguns elementos relevantes para compreensão das interrelações entre Estado, cidadania, direitos e emancipação na sociedade burguesa. A autora reconhece o caráter intrinsecamente contraditório do chamado Estado social, engendrado pelas seguintes características: o reconhecimento dos direitos sociais como resultado simultâneo da luta de classes e das condições objetivas das forças produtivas; a impossibilidade de tais direitos superarem as desigualdades inerentes ao capitalismo. A autora, também, faz uma crítica à amplamente conhecida cidadania marshalliana ${ }^{7}$, destacando que a cidadania burguesa e a igualdade formal por ela proporcionada não podem ser confundidas com a emancipação humana, pois, "[...] embora os direitos sociais possam conflitar eventualmente com os interesses da acumulação, não estabelecem com estes uma relação antagônica” (BOSCHETTI, 2016, p. 54).

Nos marcos de tal limitação inerente às políticas e direitos sociais como dimensões da emancipação política, a autora concebe que a defesa por direitos pode constituir-se em mediação na luta pela emancipação humana, principalmente à luz das tensões que isto pode implicar a disputa das massas com o capital. Assim, Boschetti (2016) conclui que é imprescindível fazer das lutas pelos direitos de cidadania "[...] uma base material de tensionamento contra o capital" (BOSCHETTI, 2016, p. 59).

Dentre as análises expostas, verificam-se dois grandes eixos de convergência entre Lessa (2007), Tonet (2015) e Boschetti (2016): a reivindicação do marxismo e da relevância desse campo teórico para a compreensão da realidade social contemporânea e para o direcionamento das lutas da classe trabalhadora; a concepção do horizonte da emancipação humana como fundamental diante da barbarização do capitalismo e da agudização da luta de classes.

No entanto, verifica-se que os autores divergem na interpretação do papel que as políticas e os direitos sociais podem exercer no caminho para a emancipação humana. A visão de Lessa (2007) é radical e abstrata, permeada por um árido ceticismo acerca de toda e qualquer forma de emancipação política como caminho para a superação do capitalismo, na medida em que o autor concebe que as lutas pela emancipação humana devem ocorrer, unicamente, no plano extraparlamentar, sem incorporar nenhuma forma de ação por dentro do Estado capitalista.

Tonet (2015), por seu turno, não ignora o papel contraditório das políticas sociais, tampouco sua importância na luta pela emancipação humana, desde que isto seja feito em um contexto de recuperação da consciência revolucionária do proletariado. Assim, o autor não rejeita as lutas por direitos e políticas sociais, mas aponta que devem estar subordinadas a um projeto mais amplo, no terreno extraparlamentar (TONET, 2015). Por sua vez, Boschetti (2016), reconhecendo o caráter limitado e contraditório da política social capitalista, defende que esta

\footnotetext{
${ }^{6} \mathrm{Na}$ concepção de Boschetti (2016), a denominação "Estado social” é uma designação que concebe que os direitos implantados por meio das polític as sociais não possuem o condão de eliminar a natureza capitalista do aparato estatal nos países em que se consolidou.

7 Em seu tex to sobre o status de cidadania e seus impactos no sistema de classes capitalista, Marshall (1967), argumenta que tal status é composto pelos elementos civis, políticos e sociais. Em sua concepção, a igualdade de status, no Século XX, tornou-se mais importante do que a igualdade de renda. Para uma crítica à análise marshalliana, consultar Barbalet (1989).
}

Argum., Vitória, v. 10, n. 2, p. 148-160, maio/ago. 2018. 
pode ser um mecanismo de mediação para a emancipação humana, a partir dos tensionamentos que sua defesa engendra no confronto contra o capital.

A argumentação incorporada neste artigo compartilha a concepção de Boschetti (2016), no que corresponde às tensões que a política social engendra em relação ao capital no contexto de agudização da crise. Também, incorpora a visão de Tonet (2015), no sentido de que a defesa das políticas sociais não pode ocorrer de uma forma unilateral e isolada, mas deve estar articulada a um projeto revolucionário mais amplo, que não se restrinja às lutas no aparelho do Estado. Por outro lado, rejeita-se o caráter abstrato da análise de Lessa (2007), que defende a luta pela supressão do capitalismo sem considerar o fato de que a superação de tal sistema exigirá certo grau de articulação com suas próprias bases materiais. Em contraposição à concepção de Lessa (2007), argumenta-se que o comunismo desenvolver-se-á do próprio capitalismo, assim como a sociedade burguesa nasceu do ventre da ordem feudal. Marx (2012, p. 29; grifos no original) expôs o caráter peculiar da transição para o comunismo em uma passagem da Crítica do Programa de Gotha:

Nosso objeto aqui é uma sociedade comunista, não como ela se desenvolveu a partir de suas próprias bases, mas, ao contrário, como ela acaba de sair da sociedade capitalista, portanto trazendo de nascença as marcas econômicas, morais e espirituais herdadas da velha sociedade de cujo ventre ela saiu (MARX, 2012, p. 29).

Portanto, com base no fundamento teórico de que a conquista da emancipação humana não ocorrerá de forma abstrata, a partir de suas próprias bases, mas necessariamente a partir das bases materiais da sociedade burguesa, defende-se que a política social pode constituir-se em uma mediação na complexa luta pela abolição das relações de produção capitalistas, conforme será problematizado na próxima seção.

\section{Política social e emancipação humana: algumas proposições}

Esta seção está direcionada à sinalização de algumas sugestões acerca de como a política social pode se constituir em mediação para a emancipação humana. Antes de tal abordagem, porém, é relevante tecer breves considerações acerca das limitações e contradições que são inerentes à política social no capitalismo.

Pesquisadores brasileiros consagrados na área do Serviço Social, como Faleiros (2009) e Behring e Boschetti (2011), convergem no fato de que a categoria da totalidade é fundamental ao estudo da política social, pois seu sentido, limites e possibilidades no capitalismo somente podem ser apreendidos quando se concebe a realidade como um todo complexo e dinâmico, o qual é permeado por múltiplas determinações, que relacionam-se entre si. Dessa feita, uma análise das políticas sociais no capitalismo que respeite a dialética-materialista marxiana deve refutar as perspectivas teórico-metodológicas unilaterais, como as pluralistas e as estruturalistas ${ }^{8}$.

A política social do Estado capitalista tem um caráter contraditório que lhe é imanente, e isto está diretamente relacionado aos seguintes aspectos: gera efeitos favoráveis para a classe

8 Análises críticas acerca das diferentes perspectivas teórico-metodológicas no estudo da política social podem ser encontradas em Behring e Boschetti (2011, p. 25-46) e Gough (1982).

Argum., Vitória, v. 10, n. 2, p. 148-160, maio/ago. 2018. 
trabalhadora, pois engendra, em maior ou menor grau, melhores condições de vida e trabalho; impõe algum limite à subsunção do trabalho ao capital; favorece o ambiente da acumulação capitalista, pois possibilita a reprodução da mercadoria força de trabalho e, no caso das políticas que geram benefícios monetários, incentiva o consumo; não se trata de mera concessão do capital e do Estado, devendo ser compreendida à luz da correlação de forças entre capital e trabalho (GOUGH, 1982; FALEIROS, 2009; BEHRING; BOSCHETTI, 2011).

À luz dessas contradições, as políticas sociais constituem-se em instrumentos que estão no âmbito da emancipação política, e é exatamente essa circunstância que engendra os seus limites. A afirmação de Marx (2010), no sentido de que "[...] a elevação política do homem acima da religião compartilha de todos os defeitos e de todas as vantagens de qualquer el evação política" [...] (MARX, 2010, p. 39, grifos do autor), pode ser plenamente aplicada à política social. Trata-se de uma elevação política, dotada da vantagem de impor algum limite à exploração do trabalho, mas, ao mesmo tempo, permeada pela desvantagem do fato de que os pressupostos da ordem burguesa, como a propriedade privada e o trabalho assalariado, continuam amplamente vigentes com as políticas sociais.

Portanto, a concepção, defendida neste artigo, de que a política social pode se constituir em instrumento funcional às lutas pela emancipação humana não ignora suas contradições e limites nos marcos do capitalismo, tampouco incorpora quaisquer tipos de ilusões reformi stas, as quais Mandel (1982), apropriadamente, denominou de “[...] ilusões quanto à possibilidade de 'socialização através da redistribuição"' (MANDEL, 1982, p. 339).

Parte-se, então, para a argumentação acerca de como a política social pode se constituir em mediação para a emancipação humana no capitalismo contemporâneo e, em caráter preliminar, propõem-se três formas: como objeto de pesquisa científica; como mecanismo de homogeneização e unificação dos interesses e reivindicações dos trabalhadores; como instrumento garantidor de condições materiais mínimas de existência da classe trabalhadora.

Em primeiro lugar, defende-se que, como objeto de estudo, a política social pode ser instrumento para as lutas revolucionárias, pois permite o diagnóstico das condições materiais de vida dos trabalhadores e da luta de classes em determinado estágio do capitalismo. De modo geral, a política social como campo de pesquisa científica se constitui em um ramo relativamente novo, constituído, primordialmente, a partir da segunda metade do século XX, ou seja, no período em que as políticas sociais e o Estado social se desenvolveram e se generalizaram. Estudos como o de Marshall (1967) e o de Gough (1982), respeitadas as diferentes perspectivas teórico-metodológicas desses autores, são expressões desse maior interesse científico pela política social no Reino Unido.

Pereira (2016, p. 80) assinala que a política social é um ramo de conhecimento interdisciplinar, o qual "[...] interessa-se preponderantemente por conhecer e explicar de forma crítica o bem-estar para o qual empiricamente ela deve estar a serviço [...], entre tantas outras questões que fazem parte do universo complexo e conflituoso desse estudo acadêmico" (PEREIRA, 2016, p. 8o). No Brasil, o estudo das políticas sociais é executado por profissionais de diversas áreas, como Ciência Política, Economia e Ciências da Saúde, mas as pesquisas na área do Serviço Social são, sem dúvida, as que desenvolveram as discussões teóricas e conceituais mais sistematizadas sobre o tema. Behring e Boschetti (2011), ao apontarem a inter-

Argum., Vitória, v. 10, n. 2, p. 148-160, maio/ago. 2018. 
locução crítica que envolveu diversos autores do Serviço Social desde os fins da década de 1980, destacam a relevância dos estudos na área para a compreensão da realidade social brasileira:

Assim, temos desde então uma compreensão mais profunda dos acontecimentos dos anos 1990, dos impactos do neoliberalismo para as políticas sociais de uma maneira geral, mas também na particularidade brasileira e latino-americana, com a publicação de livros, teses e dissertações, bem como o desenvolvimento de linhas de pesquisa nos programas de pós-graduação e também nas graduações (BEHRING; BOSCHETTI, 2011, p. 19).

Esses estudos científicos que têm como objeto a condição da política social são extremamente úteis à identificação das condições de vida da classe trabalhadora e da luta de classes sob a égide da crise estrutural do capital e da ofensiva burguesa neoliberal.

A título de exemplo, é possível fazer menção a estudos sobre as tendências da Seguridade Social nos marcos do neoliberalismo, como o de Mota (2015), que demonstrou a tendência de produção, por um lado, do cidadão-trabalhador do grande capital, público-alvo dos mecanismos privados de proteção social, e, por outro, do cidadão-pobre, ao qual restam os precários serviços públicos. Estudos como este são paradigmáticos para compreender a inserção material da classe trabalhadora em um contexto no qual a proteção social sofre profundas reconfigurações, com a finalidade de melhor servir ao contexto contemporâneo da acumulação. Também é possível citar estudos que problematizam, criticamente, o financiamento e o destino do fundo público no Brasil, como o de Salvador (2010). Essa espécie de análise fornece material maciço para diagnóstico da opressão burguesa contra os subalternos no país, pois a política econômica demandada pelo capital oprime a classe trabalhadora - que paga proporcionalmente mais tributos - para fins de destinação de recursos à acumulação, especialmente por meio da dívida pública.

Pelo fato de a política social ser um objeto de estudo menos abstrato e mais próximo do dia a dia dos trabalhadores, pesquisadores da área tendem a ter uma relação mais próxima com organizações e movimentos sociais, facilitando o diálogo e a consciência política da classe oprimida. De acordo com Behring e Boschetti (2011), a agenda de lutas e discussões em torno das políticas sociais aproxima as instituições políticas de organização dos assistentes sociais e favorecem o estabelecimento de "[...] uma interlocução social ampla e profícua com os movimentos sociais, dos demais trabalhadores e populares” (BEHRING; BOSCHETTI, 2011, p. 20).

Enfim, em uma conjuntura na qual, segundo Tonet (2015), os movimentos da classe operária perderam o seu conteúdo revolucionário em virtude da adoção da via reformista, o estudo da política social pode ajudar a compreender as angústias e inquietações que permeiam as condições de vida, trabalho e lutas da classe trabalhadora brasileira, o que seria um primeiro passo na retomada das lutas revolucionárias.

Uma segunda forma por meio da qual a política social pode favorecer as lutas pela emancipação humana seria como mecanismo de homogeneização e unificação dos interesses e reivindicações dos trabalhadores. Sabe-se que algumas das expressões mais devastadoras da reestruturação produtiva pós-fordista levada a cabo pelo capital, especialmente a partir da década de 1970, foram os impactos na morfologia do trabalho e, com efeito, na organização

Argum., Vitória, v. 10, n. 2, p. 148-160, maio/ago. 2018. 
política do operariado. Antunes (2005) escla rece que o processo de implantação dos métodos e técnicas toyotistas de gestão do trabalho, bem como a adoção de vínculos empregatícios flexíveis, tornaram a classe trabalhadora mais heterogênea, complexificada e fragmentada, de modo que suas formas de organização e pautas de reivindicações são profundamente pulverizadas.

As lutas pelas políticas sociais, especialmente as de maior abrangência, — como Saúde, Previdência Social e Educação - podem ser utilizadas como instrumentos de amenização da fragmentação engendrada pela reestruturação produtiva e podem ser utilizadas para fins de unificação dos interesses e pautas dos trabalhadores. A recente ofensiva à proteção previdenciária no Brasil, constante na Proposta de Emenda Parlamentar (PEC) no 287/2016, foi um exemplo embrionário de como uma política social abrangente tem a potencialidade de congregar diversas frações da classe trabalhadora na luta contra a imposição de restrições de acesso à proteção social: trabalhadores do setor privado; servidores públicos; trabalhadores rurais; autônomos; incapacitados para o trabalho assalariado; empregadas domésticas; professores; idosos.

Uma terceira proposição acerca de como as políticas sociais podem funcionar a serviço da emancipação humana é a circunstância de que estas atuam, em maior ou menor medida, como garantidoras de condições materiais mínimas de existência da classe trabalhadora. De acordo com Barbalet (1989,), “[...] com algumas restrições, pois, é possível afirmar que certos direitos (embora não os direitos em geral) podem servir como meio de aquisição social de condições materiais que doutra maneira poderiam não ser acessíveis" (BARBALET, 1989, p. $35)$.

Na sociedade burguesa, o processo de valorização do capital e reprodução da ordem social pressupõe a exploração do trabalhador pelos capitalistas proprietários dos meios de produção, configurando uma conjuntura na qual "[...] todo seu tempo disponível é por natureza e por direito tempo de trabalho, portanto, pertencente à autovalorização do capital” (MARX, 1983, p. 211). Sob a regência de tal sociabilidade, as políticas sociais podem proporcionar à classe trabalhadora duas espécies de condições materiais que garantem uma inserção mais favorável nas lutas contra o capital. Por um lado, medidas que permitem a limitação do tempo de trabalho e a expansão do tempo de não trabalho, como a limitação da jornada de trabalho, as férias, o descanso semanal remunerado, os benefícios previdenciários. Por outro lado, políticas que ensejam condições mínimas de subsistência, como o acesso a salários e/ou benefícios monetários que atendam às necessidades alimentares do trabalhador e de sua família, serviços de saúde bem estruturados, condições de moradia salubres, dentre outros.

Certamente, sob o contexto da opressão burguesa, é mais fácil educar o trabalhador para a política revolucionária quando este está dotado de condições mínimas de subsistência, e, nesse processo, a política social pode exercer um papel estratégico.

Fica evidente, a partir das proposições aqui expostas, que os debates acerca da política social não podem adquirir um caráter meramente abstrato, e o pressuposto fundamental sob o qual estruturam-se as formas que a convertem em mediação para a emancipação humana é o fato de que a política social está presente no dia a dia da classe trabalhadora. A política so-

Argum., Vitória, v. 10, n. 2, p. 148-160, maio/ago. 2018. 
cial está presente, por exemplo, nas escolas públicas da Educação Básica, nos hospitais do Sistema Único de Saúde (SUS), nas agências do Instituto Nacional do Seguro Social (INSS), nos equipamentos do Sistema Único de Assistência Social (SUAS). Em decorrência de tal particularidade, ainda que limitada por ser uma conquista nos marcos da emancipação política, a política social não pode ser abstraída do projeto revolucionário, direcionado à emancipação humana, pois é parte constitutiva da vida e da realidade da classe oprimida pelo capital.

\section{CONSIDERAÇÕES FINAIS}

Diante do debate que atualmente inquieta pesquisadores/as da política social, especialmente do Serviço Social brasileiro, este artigo teve o objetivo geral de traçar algumas diretrizes do debate marxista sobre emancipação política e emancipação humana no capitalismo e, como objetivo específico, pretendeu sinalizar algumas proposições acerca de como a política social pode se constituir em mediação para a emancipação humana.

Inicialmente, apresentou-se breve resgate teórico da concepção marxiana a respeito dos aspectos que conformam a essência da emancipação política e da emancipação humana Após apresentação das concepções de autores marxistas do Serviço Social brasileiro sobre o papel que as políticas e os direitos sociais podem exercer ou não nas lutas pela emancipação humana, incorporou-se a concepção de Tonet (2015) no sentido de que a única maneira de a política social ser mecanismo para alcance da emancipação humana é que sua defesa não ocorra de forma unilateral e isolada, mas que faça parte de um projeto revolucionário mais amplo e complexo. Na segunda parte do artigo, após reconhecimento do caráter contraditório e limitado das políticas sociais, foram expostas três propostas acerca de como a política social pode se constituir em mecanismo mediador nas lutas pela emancipação humana: como objeto de estudo; como mecanismo de homogeneização e unificação das reivindicações dos trabalhadores; como garantidora de condições materiais mínimas de existência.

Salienta-se que as sugestões apresentadas neste texto não são definitivas sobre o tema, mas se constituem em um esforço preliminar de síntese e sistematização sobre essa temática, pois as relações sociais que permeiam esse complexo debate estão em constante movimento e potencializam-se nos marcos da atual conjuntura de agudização da crise do capital e da ofensiva burguesa.

Para além do juízo de valor que possa ser feito acerca das proposições apresentadas na segunda parte deste trabalho, a análise permitiu apreender três inferências fundamentais: a primeira é o reconhecimento da necessidade de superar o capitalismo e colocar a emancipação humana no horizonte das lutas da classe trabalhadora, o que é consenso entre os autores marxistas visitados neste texto; a segunda constatação importante é o reconhecimento, a partir de Marx (2012), de que a conquista da emancipação humana não ocorrerá de forma dissociada da ordem social vigente, e, sob esse fundamento, concebe-se que a política social capitalista pode se constituir em mediação nas lutas pela superação do capitalismo; a terceira inferência é que as potencialidades das políticas sociais como instrumentos nas lutas revolucionárias estão diretamente relacionadas ao fato de que estas não são mediações abstratas, como concebe Lessa (2007), mas são mecanismos amplamente presentes no cotidiano da classe trabalhadora.

Argum., Vitória, v. 10, n. 2, p. 148-160, maio/ago. 2018. 
Em última instância, diante da atual conjuntura de agudização da ofensiva capitalista contra a classe trabalhadora nos contextos brasileiro, latino-americano e mundial, é relevante resgatar a concepção classicamente apresentada por Marx e Engels (2010), em 1848, de que a revolução proletária e, com efeito, a emancipação humana são inevitáveis: “[...] a burguesia produz, sobretudo, seus próprios coveiros. Seu declínio e a vitória do proletariado são igualmente inevitáveis" (MARX; ENGELS, 2010, p. 51). Nesses tempos reacionários, o otimismo revolucionário deve prevalecer sobre o imobilismo e o ceticismo e tal concepção, talvez, seja a maior contribuição da obra marxiana para as lutas dos oprimidos pelo capital.

\section{REFERÊNCIAS}

ANTUNES, R. Os sentidos do trabalho: ensaio sobre a afirmação e a negação do trabalho. 7. ed. São Paulo: Boitempo, 2005.

BARBALET, J. M. A cidadania. Lisboa: Estampa, 1989.

BEHRING, E.; BOSCHETTI, I. Política Social: fundamentos e história. 9. ed. São Paulo: Cortez, 2011.

BENSAÏD, D. Apresentação. In: MARX, Karl. Sobre a questão judaica. São Paulo: Boitempo, 2010. p. 9-29.

BOSCHETTI, I. Assistência social e trabalho no capitalismo. São Paulo: Cortez, 2016.

FALEIROS, V. A política social do estado capitalista: as funções da previdência e assistência sociais. 12. ed. São Paulo: Cortez, 2009.

GOUGH, I. Economía política del Estado del bienestar. Madrid: H. Blume Ediciones, 1982.

LESSA, S. A Emancipação Política e a Defesa de Direitos. Revista Serviço Social e Sociedade, São Paulo: Cortez, jun. 2007. Disponível em:

$<$ http://sergiolessa.com.br/uploads/7/1/3/3/71338853/emancipacao_dirt_2oo8.pdf>. Acesso em: 30 abr. 2018.

MANDEL, E. O capitalismo tardio. São Paulo: Abril Cultural, 1982.

MARSHALL, T. H. Cidadania, classe social e status. Rio de Janeiro: Zahar, 1967.

MARX, K. Crítica do Programa de Gotha. São Paulo: Boitempo, 2012. (Coleção MarxEngels).

MARX, K. Sobre a questão judaica. São Paulo: Boitempo, 2010. (Coleção Marx-Engels).

MARX, K. O capital: crítica da economia política. São Paulo: Abril Cultural, 1983.

MARX, K.; ENGELS, F. Manifesto Comunista. 1. ed. rev. São Paulo: Boitempo, 2010.

Argum., Vitória, v. 10, n. 2, p. 148-160, maio/ago. 2018. 
MOTA, A. E. Cultura da crise e seguridade social. 7. ed. São Paulo: Cortez, 2015.

PEREIRA, C. P. Proteção social no capitalismo: crítica a teorias e ideologias conflitantes. São Paulo: Cortez, 2016.

SALVADOR, E. Fundo público e seguridade social no Brasil. São Paulo: Cortez, 2010.

TONET, I. Qual política social para qual emancipação? SER Social, Brasília, v. 17, n. 37, p. 279-295, jul./dez.2015.

Thais Soares CARAMURU

Possui graduação em Giências Econômicas pela Universidade Federal Rural do Rio de Janeiro (2011). Especialização em Relações Internacionais na Universidade de Brasília (2015). Mestrado em Política Social no Programa de Pós-Graduação em Política Social da Universidade de Brasília (2017). Atividade profissional atual como Analista Técnica de Políticas Sociais no Ministério dos Direitos Humanos. 